\title{
ACHIEVEMENTS, PROBLEMS AND PROSPECTS OF THE SCIENTIFIC APPROACH AIMED FOR ENSURING RESOURCE-EFFICIENT TECHNOLOGIES IN THE CONTEXT OF PERSONNEL POLICY IN THE ENERGY SECTOR
}

\author{
Veronika M. Rostovtseva ${ }^{1,}$, and Gavriil A. Nizkodubov ${ }^{1}$ \\ ${ }^{1}$ National Research Tomsk Polytechnic University, 634050 Tomsk, Russia
}

\begin{abstract}
The article is devoted to the increasing role of human resources in the field of energy policy. Basic directions for the development of personnel policy, the ways of their implementation in the modern HR environment have been outlined. The results of the content analysis of the research on personnel policy and personnel training for the energy sector in the context of the whole spectrum of science have been introduced; certain specific features of the process have been studied.
\end{abstract}

\section{Introduction}

The energy sector has one of the strategic roles in the development of national industrial complexes, and the world economy as a whole. It is usually regarded as one of the factors of competitiveness of the national economy in the global market. Modern industry is based on the knowledge economy, so the success of this development is largely determined by the degree of the relationship between science and production, efficient use of resources. Energy is a knowledge-intensive industry and over the last twenty years about thousands of $\mathrm{Ph}$.D. dissertations have been devoted to the energy sector. These researches have been carried out mainly in the framework of technical, physical, mathematical, and economic sciences. Resource-saving technologies are considered as a new direction in the development of modern energy sector.

People carry out promotion of scientific ideas, their practical implementation. The role of human resources is steadily increasing. It has been proved that the economic model based on knowledge is the most promising because it allows us to use existing intellectual and labor resources more efficiently [1]. Since the economic model constitutes the main part of the regular employees, professional and social organizations of the energy sector, subsequently, the personnel policy must also meet the changing situation, i.e. undergo certain changes. The problem of status and human resources development cannot be considered solely in economic terms, it is also relevant to the field of sociology, psychology

${ }^{*}$ Corresponding author: kachalov@tpu.ru 
and pedagogy, which are associated with the development of an individual, its education and training, as well as issues of professional competence. However, similar studies have been carried out ten times less. This fact prompted us to attempt to identify the achievements and problems of an individual, as well as to offer our own vision of the prospects for the scientific approach aimed for ensuring resource-saving technologies in the context of personnel policy in the energy sector.

\section{Personnel policy in the energy sector}

Personnel work is the activity of individual enterprises or the whole branch aimed at the formation of their personnel. By personnel policy is usually meant a set of those principles, methods and forms of institutional mechanisms that allow developing goals and objectives in order to maintain, strengthen and develop human resources; creating a highly efficient and cohesive team capable of responding promptly to changing market requirements. In general, the range of issues is wide enough - staff, personnel policies, personnel strategy, personnel management, development of "labor potential". In order to solve the problems some domestic and international experience has been accumulated. However, the lack of uniform solutions in human resources management, and the specifics of the industry cause a need to specify issues in relation to the energy sector.

Personnel policy is implemented through multiple strategies. In practice, the development of human resources strategies is a concept design of the industry as a whole or of individual enterprises on the development of human resources and the implementation of this plan [2]. To solve the problems associated with human resources management a new human resources strategy is required. On the one hand, the strategy should match the challenges of the modern times, and, on the other hand, - the specifics of the current conditions bearing the imprint of the prolonged economic crisis. In respect of the matter, according [2] this resulted in the outflow of skilled labor, the reorientation of the educational priorities of the youth.

There are several areas of human resources policy. For example, introduction of new technologies in the prediction of new job places and opportunities. Currently, resourceefficient technologies have become popular where leading positions belong to resource conservation. The existing achievements will be briefly described below.

In scientific terms, the broad issues of energy saving of individual production processes, including fuel economy have been. Basically, energy saving solutions, issues of energy conservation and methods of their solutions on the example of a particular region are studied. The issue is being actively considered from the perspective of economic science. A large number of scientific studies is related to the development and maintenance of special technical equipment in various branches of modern industry, guest industry, agriculture, etc.

Some scientific research works are devoted to the search of methods and development of organizational and economic power management mechanisms. In our opinion, there is unreasonably little specialized research work on developing resource-saving technologies only a small number of scientific studies can be mentioned [3-5].

Author [6] has introduced new and interesting ideas in terms of the factors that have a significant influence on modern human resources policy in the energy sector. The quoted author considers the process of finding market niches in the field of energy saving and energy efficiency management of science-based management solutions. The proposed conceptual characteristics of marketing environment reflect its condition and the basic tendencies of the development. In addition, author [7] reveals the role of the energy audit as an organizational-economic mechanism of energy companies. This, of course, must be 
taken into account for introduction of new technologies aimed at creation of new job places and opportunities.

Another area of personnel policy is closely related to the issues of human resources management. There are several ways to implement the policy. We are going to describe only three of them, which, in our opinion, are the most important. The first way is to develop special programs in order to address current and future challenges in energy industry or enterprises/companies. On the one hand, this is due to issues of innovation in the energy sector, the tools of their distribution [8]. On the other hand, - this is due to projects, which aim is to ensure resource-efficient, energy-saving technologies. For example, issues of methodology and practice of the development of comprehensive longterm energy conservation and energy efficiency programs are covered in the doctoral thesis [9]. In this respect, scientific works of S.M. Klyugin, S.M. Naumenko, I.V. Eliseeva must be noted as well. Author [10] has offered a scientific justification of technical solutions to organization of the personnel in the management system of energy enterprises; however, the author sees it through the prism of fiscal responsibility.

System management of personnel innovative activity should be considered as one of the resources of enterprises competitiveness in any industry. The essential difference between the present stage of the development of the energy sector from the previous one is due to the new look on the perception of the role and functions of the personnel resource in energy industry. Firstly, the human resource is capable of becoming human capital and can become profitable for the industry/enterprises. Secondly, the human resource management as a subject becomes a "domestic consumer", which allows the industry/company to develop successfully. According to [2] it is the point of view, which makes it possible to overview a modern personnel resource as a competitive advantage for industries/businesses.

The second way of implementation of the given direction of the personnel policy is to develop a special motivational tool for raising interest and satisfaction of personnel. Traditionally, it is associated with the introduction of certification procedures that can be implemented at different levels. For example, they can be implemented as a set of key performance indicators of industrial enterprises [11], or as a form of performance appraisal [12]. It is important to emphasize that the regulation of competitive relations and stimulation has been mainly undertaken in the search for economic mechanisms to address human resources management issues.

The third way of implementation of the personnel management is to create a modern staff selection system. The third way is usually seen in the wider context of management. Traditionally, there is a difference between open and close personnel policies. The open policy is characterized by willingness to employ any worker on condition that he/she has appropriate qualifications and skills. The close personnel policy is focused on hiring new staff only from a lower-level official job position. All subsequent replacements deal only with the number of employees at the enterprise. There are some social studies of the issue. However, the specificity of the energy sector is not taken into account. The selection of personnel depends on what knowledge, skills, and abilities, motivation of personnel resources are required for the industry/enterprise, and thus will be profitable. The current challenge is to determine the feasibility of training personnel on the ground (in terms of corporate training as well), encourage personnel to update existing competencies, or to dismiss personnel and attract staff from outside.

The main condition is the current level of competences that can be a result of personnel training and experience. Due to the competency component, view on human resources and its assessment proceeds from the category of economic issues into psychological and pedagogical categories. There are many issues in connection with the quality of training and assessment of intellectual capital in training of experts in technical universities. According to the just assertion of [13], current challenges have led to the need to form a 
human of innovative type. The author has also determined the status of twelve innovative human traits due to imperative challenges of modern innovation environment. Mobility and the qualification and professional potential are among them.

Mobility of staff resources may occur in three forms: territorial, that is associated with the change of residency and finding a new job in a city or in the country; vertical, i.e. climbing up the career ladder within the same type of activity; professional, that means a change in the type of activity.

Qualification and professional potential as a status characteristic of personnel resources can be represented by a number of factors: education - further training; additional qualities and skills that arise under the pressure of modern challenges and innovative environment, in particular, there is a need to know at least one foreign language, as well as to focus on the world, rather than a local practice; competency moment, the essence of which is seen as the ability of a human to independently obtain new information and to put acquired knowledge and skills into practice.

If we turn to the definition of the nature and content of the competences, it can be found out that the task cannot be completely resolved within the framework of economic sciences, some incentives will not be enough. These issues must be addressed mainly in the context of pedagogy and psychology.

\section{Psycho-pedagogical perspective view on the development of human resources in the energy sector}

As a whole, pedagogy does not ignore questions of training for various sectors of the domestic industry where much attention is paid to training of engineers. Interesting historical review of this issue, determination of the process characteristics, depending on the characteristics and needs of a particular region, has been made. As a part of a series of historical sciences, the research devoted to training of workers and engineering staff for some industries on the example of development in the second half of the twentieth century has been carried out. Despite that, the energy sector has not been researched yet.

With regard to vocational education and training of engineering students, the study mainly deals with interdisciplinary connections, formation of a mathematical thinking culture, technologies for formation of a system-evolutionary style of thinking, revealing of pedagogical conditions for formation of professionally significant personality traits, abilities of students et al.

However, the issues concerning training of future professionals in the field of energy and electrical and heating engineering have been rarely raised. Basically, much attention is paid to the technologies used in the educational process on the example of a single discipline. Often it is training in terms of a general education cycle in a technical college, for example, physics. Author [11] mentions application of remote technologies in the system of independent student work in computer science. T.N. Petikova characterizes the competence-oriented technology for training competitive engineering specialists in nontechnical universities. Author [14] describes the technology of realization of continuity of professional training in colleges and universities. M.K. Medvedeva analyzes effectiveness of e-learning. There is also more common research on the formation of certain types of competencies in foreign languages: the reflective foreign language competence of students of power specialties [15].

The scientific research on the pedagogical issues concerning formation and development of professional competences is particularly scarce. In this regard, scientific study of E.V. Shischenko on the formation of professional competencies of technical students on the basis of integration of electrotechnical disciplines has become particularly 
interesting. We also consider it important to draw attention to scientific work [16], which deals with the formation of professional competences in the field of personnel management of university students. Despite the fact that the subject "Fundamentals of personnel management" is rarely included in training of future engineering specialists, the results obtained by the author are rather interesting and significant.

At present, almost all industries are experiencing an increased demand for qualified personnel in the production of different levels, from skilled workers to senior professionals. In that case, when the issue concerning formation of professional competences of the expert in the field of modern energy, it is important to have a complete idea of what knowledge, skills, abilities, should become target directions. They must meet modern requirements of the industry and help to overcome the deficit of technical specialists. A clear qualitative analysis and forecast of the staff situation at different levels substitutes the basis of personnel policy for the energy sector to ensure resource-efficient technologies.

\section{Conclusions}

Personnel policy is based on the appropriate strategies, and its implementation is carried out in several directions. The strategies have become of paramount importance since there is the need to introduce resource-efficient technologies and to manage staff in accordance with the requirements of the competitive environment and the specificity of the energy sector.

Historical retrospective of the training arranged for workers and engineers of the domestic power industry, as well as comparative benchmarking with similar foreign practice have become of great interest.

There is a growing popularity of the competence-based approach in training of competitive specialists for various industries. Despite the advances in the scientific study of vocational training for engineers in general, it is necessary to overcome the shortage of scientific educational research on the problems of formation and development of proper professional competences for specialists in the field of energy.

Modern personnel policy of the energy sector should be based on a clear qualitative analysis of human resources and the forecast of the staff situation at different levels.

\section{References}

1. A.A. Shiryaev Knowledge Management in the reorientation of the Russian economy on an innovative path of development (Ph.D., Diss., Moscow, 2012)

2. E.V. Mochalnikova Formation of personnel strategy of manufacturing enterprises in the competitive environment (Ph.D., Diss., Irkutsk, 2005)

3. I.F. Kurunov Development of resource blast smelting technology, based on its research and mathematical modeling (Dokt, Diss., Moscow, 2003)

4. S.N. Romanov Organizational-economic mechanisms of development and industrial development of energy-saving technologies: the case of domestic gas savings (Ph.D., Diss., Moscow, 2010)

5. A.S. Savenko Resource saving management in the enterprise, based on the analysis of energy reserves (Ph.D., Diss., Moscow, 2012)

6. V.P. Vershinin Conceptual characteristics (state and basic trends) of the marketing environment in search for market niches in the field of energy saving and energy efficiency management of science-based management decisions (Dokt, Diss., Sochi, 2011) 
7. A.S. Mozgova The organizational and economic mechanism of increase of energy efficiency of the oil and gas enterprises through energy audits (Ph.D., Diss., Moscow, 2014)

8. T.A. Krolin The mechanism and instruments of distribution of innovations in the field of energy saving (Ph.D., Diss., Moscow, 2012)

9. I.A. Bashmakov Development of integrated long-term programs in energy saving and energy efficiency: methodology and practice (Dokt, Diss., Moscow, 2013)

10. T.A. Prokhorova T.A. Organization of personnel management system of power plants as the center of financial responsibility (Ph.D., Diss., Barnaul, 2007)

11. N.M. Kuznetsov N.M. Development of motivation system based on key performance indicators of the enterprise efficiency: on the example of electric power (Ph.D., Diss., Moscow, 2009)

12. E.V. Spiridonova E.V. The development of the system of certification for electrical safety of electrical installation personnel (Ph.D., Diss., Chelyabinsk, 2004)

13. R.G. Shangaraev Modern challenges and the formation of the person of innovative type (Ph.D., Diss., Ivanovo, 2006)

14. Z.M. Shakurova Technology of realization of continuity of professional training in the system professional school - higher school. On the example of power specialties (Ph.D., Diss., Kazan, 2002)

15. L.A. Sobinova Students training in the professional focused foreign-language reading using an electronic manual (Ph.D., Diss., Nizhny Novgorod, 2016)

16. L.L. Kifa Formation of professional competence in the field of personnel management at students of higher education institution: on the example of the discipline "A human resource management basis" (Ph.D., Diss., Tolyatti, 2012) 